\title{
Associations between the use of social networking sites and unhealthy eating behaviours and excess body weight in adolescents
}

\author{
Hugues Sampasa-Kanyinga ${ }^{1 *}$, Jean-Philippe Chaput ${ }^{2,3}$ and Hayley A. Hamilton ${ }^{4,5}$ \\ ${ }^{1}$ Ottawa Public Health, Ottawa, Ontario K2G 6J8, Canada \\ ${ }^{2}$ Healthy Active Living and Obesity Research Group, Children's Hospital of Eastern Ontario Research Institute, Ottawa, Ontario \\ K1H 8L1, Canada \\ ${ }^{3}$ Department of Pediatrics, Faculty of Medicine, University of Ottawa, Ottawa, Ontario K1H 8L1, Canada \\ ${ }^{4}$ Centre for Addiction and Mental Health, Toronto, Ontario M5S 2S1, Canada \\ ${ }^{5}$ Dalla Lana School of Public Health, University of Toronto, Toronto, Ontario M5T 3M7, Canada
}

(Submitted 1 June 2015 - Final revision received 14 July 2015 - Accepted 12 August 2015 - First published online 24 September 2015)

\section{Abstract}

Unhealthy eating behaviour and excess body weight have been related to sedentary behaviour, particularly screen time, in adolescents; however, little is known about their associations with the use of social networking sites (SNS). We investigated the associations between time spent using SNS and unhealthy eating behaviours (including breakfast skipping, consumption of sugar-sweetened beverages (SSB) and energy drinks) and body weight in adolescents. Data on 9858 students (mean age: 15.2 (sD 1.9) years) in grades 7 through 12 were derived from the 2013 cycle of the Ontario Student Drug Use and Health Survey - a cross-sectional school-based survey of middle and high school students. The majority (81.5\%) of students reported daily use of SNS and an additional $10.7 \%$ reported using them on an irregular basis. Multivariate logistic regression analyses revealed that the use of SNS was associated with increased odds of skipping breakfast $\left(P_{\text {trend }}<0.01\right)$ and consuming SSB $\left(P_{\text {trend }}<0.01\right)$ and energy drinks $\left(P_{\text {trend }}<0.01\right)$ in a dose-response manner with adjustments for age, sex, ethnicity, socio-economic status, tobacco, alcohol and cannabis use as well as BMI. However, there was no evidence of a significant association between use of SNS and BMI before or after adjusting for all the covariates and unhealthy eating behaviours. In conclusion, our results suggest associations between the use of SNS and unhealthy eating behaviours among youth. Given the popularity of SNS, more efforts are needed to better understand the impact of social networks on eating behaviours and risk of excess weight.

Key words: Social networking sites: Sugar-sweetened beverages: Energy drinks: Skipping breakfast: Overweight: Obesity

Adolescence is a time when healthy behaviours are being learnt and adopted $^{(1)}$. Eating well, being active and feeling good about oneself are important for increasing quality of life and physical function. These behaviours are also essential for the development and learning of adolescents. Unhealthy eating behaviours such as breakfast skipping and consumption of sugar-sweetened beverages (SSB) have been associated with obesity and other chronic diseases ${ }^{(2-6)}$; however, the evidence is much stronger for SSB. The prevalence of childhood obesity has reached epidemic levels, and Canada has been shown to have one of the highest prevalence of obesity in children and adolescents in the world ${ }^{(7)}$. This is a public health concern because obesity during childhood significantly increases the likelihood of obesity during adulthood, a host of illnesses and premature mortality ${ }^{(8,9)}$.

Although the causes of childhood obesity remain unclear, it is well established that factors that contribute to childhood obesity include those that increase energy intake and decrease expenditure - for example, sedentary activities such as watching television or playing video games are well known to impact energy expenditure, but also lead to poor eating habits and increase energy intake ${ }^{(10-12)}$. Consumption of SSB has also been associated with higher body weight and risk of obesity because of the added sugar, low satiety and incomplete compensation for total energy ${ }^{(13)}$. Several studies have also indicated that youth who skip breakfast are at increased risk of weight gain ${ }^{(2,14)}$. Although the mechanisms by which breakfast skipping contributes to the development of obesity is unclear, several potential mechanisms have been suggested, including decreased energy expenditure, increased daily total energy intake and increased energy storage ${ }^{(2,15,16)}$. To help reduce the high prevalence of obesity among youth, novel research studies are desired to identify possible innovative ways of promoting healthy behaviours and lifestyle in this population.

Social networking sites (SNS) such as Facebook, Twitter and MySpace may be good places to reach and engage youth with healthy eating and active living messages. Research has shown that sedentary activity, particularly screen time, is associated

Abbreviations: SES, socio-economic status; SNS, social networking sites; SSB, sugar-sweetened beverages.

* Corresponding author: Dr H. Sampasa-Kanyinga, fax +1 613580 9601, email hugues.sampasa@ottawa.ca 
with obesity and unhealthy eating behaviours such as consumption of SSB and energy drinks among adolescents ${ }^{(17,18)}$ and adults ${ }^{(19)}$. However, to our knowledge, the link between the use of SNS and these health-compromising behaviours is largely unknown.

SNS are web-based platforms that allow individuals to create their own personal profile and build a network of connections with other users ${ }^{(20)}$. At the same time, SNS are now being used as a tool for delivering healthcare programmes and services, education, research, intervention and even treatment ${ }^{(21-25)}$. SNS have enormous mass appeal and have become omnipresent in the daily life of many adolescents. With more than one billion Facebook users worldwide, it is important to examine how this sedentary activity may impact upon eating behaviours and body weight. Results will help identify whether these web-based platforms provide an opportunity to enhance ongoing efforts to promote healthy eating and active living in youth.

The purpose of this study was to investigate the association between time spent using SNS and unhealthy eating behaviours including breakfast skipping, consumption of SSB and energy drinks, and body weight among adolescents. More specifically, this study addresses questions of whether the use of SNS is related to unhealthy eating behaviours, overweight and obesity, and whether there is a dose-response relationship between time spent using SNS and each of these outcomes.

\section{Methods}

\section{Sample}

Data for this study were derived from the 2013 cycle of the Ontario Student Drug Use and Health Survey (OSDUHS) - a biennial province-wide survey of 7 th to 12 th grade students ${ }^{(26)}$. The OSDUHS began in 1977 and is the longest ongoing school study of adolescents in Canada. The survey, which uses a two-stage cluster design (school, class), monitors substance use, mental health, physical health, gambling and risk behaviour. The total sample in 2013 was 10272 students from forty-two school boards, 198 schools and 671 classrooms. The survey had a student participation or response rate of $63 \%$. Absenteeism (11\%) and unreturned forms or lack of parental consent $(26 \%)$ were the main reasons for non-participation among students ${ }^{(26)}$. The survey was conducted according to the guidelines laid down by the Declaration of Helsinki, and all the procedures involving human subjects were approved by the Research Ethics Board of the Centre for Addiction and Mental Health, and York University, as well as existing research review committees of the participating school boards. All the participants provided their own assent in addition to parental signed consent.

\section{Measures}

\section{Outcome measures}

Skipping breakfast. Breakfast consumption was assessed with a question that asked students on how many of the last 5 school days they had had breakfast, either at home, on the way to school or at school before classes (more than a glass of milk or fruit juice). The response options were as follows: none, 1-2, 3-4 and all $5 \mathrm{~d}$. A dichotomous variable was created to reflect regular breakfast consumers as those students who ate breakfast on all $5 \mathrm{~d}$ (coded 0) and irregular breakfast consumers as those who ate breakfast less frequently (coded 1) ${ }^{(27)}$.

Sugar-sweetened beverages consumption. Students were asked how often they drank a can, bottle or glass of pop (such as regular Coke, Pepsi, Sprite, etc.), sport drinks (such as Gatorade) or pre-sweetened tea or coffee (such as Iced Tea or Frappuccino). SSB do not include diet pop, $100 \%$ fruit juice or plain water. Response categories referred to consumption in the last $7 \mathrm{~d}$ (differentiating between 1, 2-4, 5-6 times, once each day and more than once each day) and no consumption in the last $7 \mathrm{~d}$. A dichotomous measure was constructed to represent consumption (coded 1) and nonconsumption (coded 0) of SSB in the last $7 \mathrm{~d}$ for analysis.

Energy drink consumption. Energy drink consumption was determined from a question that asked students how often they drank 'a can of a high-energy caffeine drink, such as Redbull, Rockstar, Full Throttle, Monster, etc.'. Response categories referred to consumption in the last $7 \mathrm{~d}$ (differentiating between 1, 2-4, 5-6 times, once each day and more than once each day); no consumption in the last $7 \mathrm{~d}$, but some consumption in the last 12 months; and no consumption in the last $7 \mathrm{~d}$ or in the last 12 months. A dichotomous measure was constructed to represent consumption (coded 1) and non-consumption (coded 0) of energy drinks in the last 12 months, as recently reported ${ }^{(28)}$.

$B M I$. Based on self-reported height and weight, BMI was calculated as weight divided by the square of height $\left(\mathrm{kg} / \mathrm{m}^{2}\right)$. Obesity and overweight were defined using the WHO's sex- and age-specific BMI cut-off points established for children and youth ${ }^{(29)}$. Categories included 'overweight or obese' (coded 1) and 'normal', including for our study both the normal and the underweight categories (coded 0).

\section{Explanatory variable}

Use of social networking sites. Students were asked how many hours a day they usually spend on social media websites such as Facebook, Twitter, Instagram, MySpace, either posting or browsing. Response options referred to daily use $(<1$, about 1 , 2, 3-4, 5-6 and $\geq 7 \mathrm{~h} / \mathrm{d}$ ); use, but not daily; use the internet, but never visit SNS; and do not use the internet. The use of SNS was treated as a dummy variable contrasting seven groups including 'non-users', 'visit these websites, but not daily', ' $<1 \mathrm{~h} / \mathrm{d}$ ', 'about $1 \mathrm{~h} / \mathrm{d}$ ', ' $2 \mathrm{~h} / \mathrm{d}$ ', '3-4h/d' and ' $\geq 5 \mathrm{~h} / \mathrm{d}$ '.

\section{Covariates}

Covariates included demographics, subjective socio-economic status (SES), parental education level and substance use. Demographics included age (measured in years), sex (females coded 1) and ethnicity. Ethnicity was assessed using responses to a question asking students to select one or more categories that best described their ethnic background. The categories listed were similar to those used in the 2006 Canadian Census $^{(30)}$. Students who selected only one ethnic background were grouped into five categories including white (coded 0), black (coded 1), East or Southeast Asian (coded 2), South Asian (coded 3) and other (coded 4). Students who selected multiple ethnic backgrounds were coded as other. 
Subjective SES was measured using the youth version of the MacArthur Scale of Subjective Social Status ${ }^{(31)}$. Minor modifications were made to the youth scale to assess the family's place within society. The question was presented with a drawing of a ladder with ten rungs that was described as follows: 'Imagine this ladder below shows how Canadian society is set up. At the top of the ladder are people who are the "best off" - they have the most money, the most education, and the jobs that bring the most respect. At the bottom are the people who are "worst off" - they have the least money, little education, no job or jobs that no one wants. Now think about your family. Please check off the numbered box that best shows where you think your family would be on this ladder'. A dichotomous measure was constructed to represent low $(<7$; coded 0$)$ and high $(\geq 7$; coded 1$)$ subjective SES, where low scores represent those below the mean.

Parental education was measured using the following items: 'How far did your father go in school?' and 'How far did your mother go in school?'. Response options referred to attended or graduated high school, college or university and did not attend high school. Parental education was coded (from 8 to 16 years) as the higher available response if the mother's and father's education levels differed. The sample mean (13.8 years) was used when neither parental education level was available $(n \text { 205) })^{(32,33)}$

Alcohol, tobacco and cannabis use were assessed with the following three questions: 'In the last 12 months, how often did you drink alcohol (liquor, wine, beer, coolers)?', 'In the last 12 months, how often did you smoke cigarettes?' and 'In the last 12 months, how often did you use cannabis (e.g. 'marijuana')?'. Responses were re-coded to create binary measures of the three substances: 'any use' (coded 1) or 'did not use' (coded 0).

\section{Statistical analysis}

All the statistical analyses were completed on weighted data using Stata 13.0 (StataCorp LP) and accounted for the complex sample design of the 2013 OSDUHS. Five respondents who were older than 19 years of age were excluded from the present study. Missing data were handled through list-wise deletion for all the variables except for parental education and BMI, reducing the sample size from 10272 to 9858. Cases with missing BMI were included because they represent nearly $6 \%$ of the sample. Descriptive characteristics of the participants by time spent using SNS and by each dependent variable of breakfast skipping, consumption of SSB and energy drinks, and BMI were compared by Pearson's $\chi^{2}$ adjusted for the survey design and transformed into an $F$-statistic for categorical data and by an adjusted Wald's test for continuous data. Logistic regression analysis was used to examine the associations between time spent using SNS and unhealthy eating behaviours including breakfast skipping, consumption of SSB and energy drinks, and BMI. Covariates included age, sex, ethnicity, subjective SES, parental education level, and tobacco, alcohol and cannabis use. Models for breakfast skipping and consumption of SSB and energy drinks were also adjusted for BMI, whereas models for BMI were also adjusted for breakfast skipping and consumption of SSB and energy drinks.

\section{Results}

Descriptive characteristics of the sample are shown in Table 1. About $49 \%$ of the sample was female, nearly $60 \%$ identified themselves as white and the majority were in high school (grades 9 through 12). The majority of participants were from families of higher SES, and the average parental education was nearly 14 years.

Table 2 presents the distribution of time spent using SNS by unhealthy eating behaviour and body weight status. The majority $(81.5 \%)$ of students reported daily use of SNS, and an additional $10.7 \%$ reported using them on an irregular basis. Students who engaged in unhealthy eating behaviours were more likely to use SNS at higher levels than students who refrained from unhealthy eating behaviours.

Results of the logistic regression analyses testing the associations between the use of SNS and unhealthy eating behaviours and body weight status are presented in Table 3. After adjustment for age, sex, ethnicity, subjective SES, parental education, alcohol, tobacco and cannabis use, and BMI, results indicated that adolescents who use SNS were at greater odds of skipping breakfast and consuming SSB and energy drinks, and that these associations generally increased in a dose-response manner with time spent using SNS (significant $P_{\text {trend }}$ ). A finding in

Table 1. Characteristics of the study participants (Numbers and percentages; mean values and standard deviations; $n$ 9858)

\begin{tabular}{|c|c|c|}
\hline & $n$ & $\%$ \\
\hline \multicolumn{3}{|l|}{ Age (years) } \\
\hline Mean & \multicolumn{2}{|c|}{$15 \cdot 2$} \\
\hline SD & \multicolumn{2}{|c|}{1.9} \\
\hline \multicolumn{3}{|l|}{ Sex } \\
\hline Male & 4428 & 51.4 \\
\hline Female & 5430 & $48 \cdot 6$ \\
\hline \multicolumn{3}{|l|}{ Grade } \\
\hline 7 & 1947 & 11.6 \\
\hline 8 & 1909 & $12 \cdot 4$ \\
\hline 9 & 1499 & $16 \cdot 6$ \\
\hline 10 & 1497 & $17 \cdot 1$ \\
\hline 11 & 1534 & $18 \cdot 0$ \\
\hline 12 & 1472 & $24 \cdot 3$ \\
\hline \multicolumn{3}{|l|}{ Ethnicity } \\
\hline White & 5812 & $59 \cdot 6$ \\
\hline Black & 567 & $6 \cdot 2$ \\
\hline East/SE Asian & 957 & $10 \cdot 1$ \\
\hline South Asian & 1087 & $10 \cdot 6$ \\
\hline Other & 1435 & $13 \cdot 5$ \\
\hline \multicolumn{3}{|l|}{ Subjective SES } \\
\hline Low & 2758 & 29.9 \\
\hline High & 7100 & $70 \cdot 1$ \\
\hline \multicolumn{3}{|l|}{ Tobacco use } \\
\hline No & 8471 & 81.5 \\
\hline Yes & 1387 & 18.5 \\
\hline \multicolumn{3}{|l|}{ Alcohol use } \\
\hline No & 3446 & $29 \cdot 4$ \\
\hline Yes & 6412 & $70 \cdot 6$ \\
\hline \multicolumn{3}{|l|}{ Cannabis use } \\
\hline No & 7873 & $73 \cdot 3$ \\
\hline Yes & 1985 & $26 \cdot 7$ \\
\hline \multicolumn{3}{|c|}{ Parental education level (years) } \\
\hline Mean & & \\
\hline SD & & \\
\hline
\end{tabular}

SE Asian, Southeast Asian; SES, socio-economic status. 
Table 2. Prevalence of time spent using social networking sites (SNS) by unhealthy eating behaviours and body weight status $\dagger$ (Percentages; $n$ 9858)

\begin{tabular}{|c|c|c|c|c|c|c|c|c|}
\hline & Do not use (\%) & Use, but not daily (\%) & $<1 \mathrm{~h} / \mathrm{d}(\%)$ & $1 \mathrm{~h} / \mathrm{d}(\%)$ & $2 \mathrm{~h} / \mathrm{d}(\%)$ & $3-4 h / d(\%)$ & $\geq 5 \mathrm{~h} / \mathrm{d}(\%)$ & Total sample (\%) \\
\hline Total & $7 \cdot 8$ & $10 \cdot 7$ & $14 \cdot 8$ & $19 \cdot 8$ & 19.5 & $16 \cdot 8$ & $10 \cdot 6$ & - \\
\hline \multicolumn{9}{|l|}{ Skipping breakfast ${ }^{\star \star \star} \ddagger$} \\
\hline No & $10 \cdot 2$ & 11.8 & $17 \cdot 6$ & $20 \cdot 6$ & $18 \cdot 1$ & 14.0 & 7.7 & $55 \cdot 1$ \\
\hline Yes & 4.9 & 9.4 & 11.4 & $18 \cdot 8$ & $21 \cdot 1$ & $20 \cdot 3$ & $14 \cdot 1$ & 44.9 \\
\hline \multicolumn{9}{|l|}{ Consuming $\mathrm{SSB}^{\star \star \star} \ddagger$} \\
\hline No & 11.9 & $12 \cdot 0$ & $16 \cdot 8$ & $21 \cdot 0$ & 18.9 & 13.0 & 6.5 & 17.9 \\
\hline Yes & $6 \cdot 9$ & $10 \cdot 4$ & 14.4 & 19.5 & $19 \cdot 6$ & $17 \cdot 7$ & 11.5 & $82 \cdot 1$ \\
\hline \multicolumn{9}{|c|}{ Consuming energy drinks $s^{\star \star \star} \ddagger$} \\
\hline No & $10 \cdot 8$ & $12 \cdot 7$ & $16 \cdot 3$ & $19 \cdot 6$ & 17.5 & $15 \cdot 0$ & $8 \cdot 1$ & $60 \cdot 3$ \\
\hline Yes & 3.3 & 7.7 & $12 \cdot 7$ & 19.9 & 22.5 & $19 \cdot 6$ & $14 \cdot 3$ & 39.7 \\
\hline \multicolumn{9}{|l|}{$\mathrm{BMI}^{\star *} \ddagger$} \\
\hline Normal & 7.8 & $10 \cdot 1$ & 14.4 & 20.9 & 19.4 & $17 \cdot 2$ & $10 \cdot 2$ & $70 \cdot 4$ \\
\hline Overweight/obese & 6.9 & $11 \cdot 3$ & $15 \cdot 5$ & 17.4 & $20 \cdot 8$ & $16 \cdot 8$ & $11 \cdot 3$ & $26 \cdot 1$ \\
\hline Not stated & $16 \cdot 1$ & $17 \cdot 8$ & $19 \cdot 0$ & 14.7 & $10 \cdot 9$ & 9.6 & $12 \cdot 0$ & 3.5 \\
\hline
\end{tabular}

SSB, sugar-sweetened beverages.

† Percentages in the 'total sample' column are separate from those in columns reflecting the use of SNS.

$\ddagger$ Pearson's $\chi^{2}$ adjusted for the survey design and transformed into an $F$-statistic.

${ }^{\star *} P<0.01,{ }^{\star * \star} P<0.001$.

Table 3. Associations between the use of social networking sites (SNS) and unhealthy eating behaviours and body weight status (Odds ratios and $95 \%$ confidence intervals; $n$ 9858)

\begin{tabular}{|c|c|c|c|c|c|c|c|c|}
\hline & \multicolumn{2}{|c|}{ Skipping breakfast } & \multicolumn{2}{|c|}{ Consuming SSB } & \multicolumn{2}{|c|}{ Consuming energy drinks } & \multicolumn{2}{|c|}{ Overweight/obese } \\
\hline & OR & $95 \% \mathrm{Cl}$ & OR & $95 \% \mathrm{Cl}$ & OR & $95 \% \mathrm{Cl}$ & OR & $95 \% \mathrm{Cl}$ \\
\hline \multicolumn{9}{|l|}{ Model $1 \dagger$} \\
\hline \multicolumn{9}{|c|}{ Time spent using SNS } \\
\hline Do not use & \multicolumn{2}{|c|}{1} & \multicolumn{2}{|c|}{1} & \multicolumn{2}{|c|}{1} & \multicolumn{2}{|r|}{1} \\
\hline Use, but not daily & $1.65^{\star}$ & $1 \cdot 24,2 \cdot 19$ & $1.49^{*}$ & $1.07,2.08$ & $1.99^{\star}$ & $1 \cdot 39,2 \cdot 86$ & $1 \cdot 17$ & $0.86,1.58$ \\
\hline$<1 \mathrm{~h} / \mathrm{d}$ & $1.34^{*}$ & $1.04,1.74$ & $1.47^{\star}$ & $1.08,2.00$ & $2 \cdot 54^{\star}$ & $1.84,3.50$ & 1.09 & $0.84,1.40$ \\
\hline $1 \mathrm{~h} / \mathrm{d}$ & $1.89^{*}$ & $1.36,2.64$ & $1.59^{\star}$ & $1 \cdot 18,2 \cdot 15$ & $3 \cdot 30^{*}$ & $2.43,4.49$ & 0.80 & $0.61,1.06$ \\
\hline $2 \mathrm{~h} / \mathrm{d}$ & $2 \cdot 42^{*}$ & $1.84,3.17$ & $1.77^{\star}$ & $1.39,2.25$ & $4 \cdot 19^{*}$ & $3.05,5.75$ & 1.00 & $0.77,1.28$ \\
\hline $3-4 \mathrm{~h} / \mathrm{d}$ & $3.00^{*}$ & $2 \cdot 22,4.06$ & $2 \cdot 34^{*}$ & $1.66,3.29$ & $4 \cdot 25^{\star}$ & $3 \cdot 13,5 \cdot 76$ & 0.91 & $0.71,1.17$ \\
\hline$\geq 5 \mathrm{~h} / \mathrm{d}$ & $3.80^{*}$ & $2 \cdot 77,5 \cdot 21$ & $3.02^{*}$ & $2 \cdot 12,4 \cdot 30$ & $5 \cdot 75^{\star}$ & $4.10,8.08$ & 1.09 & $0.86,1.39$ \\
\hline$P_{\text {trend }}$ & \multirow{2}{*}{\multicolumn{2}{|c|}{$<0.01$}} & \multirow{2}{*}{\multicolumn{2}{|c|}{$<0.01$}} & \multirow{2}{*}{\multicolumn{2}{|c|}{$<0.01$}} & \multirow{2}{*}{\multicolumn{2}{|c|}{ NS }} \\
\hline Model $2 \ddagger$ & & & & & & & & \\
\hline \multicolumn{9}{|l|}{ Time spent using SNS } \\
\hline Do not use & \multicolumn{2}{|c|}{1} & \multicolumn{2}{|c|}{1} & \multicolumn{2}{|c|}{1} & \multicolumn{2}{|r|}{1} \\
\hline Use, but not daily & $1.47^{*}$ & $1.11,1.96$ & $1.52^{*}$ & $1.08,2 \cdot 14$ & $1 \cdot 76^{*}$ & $1 \cdot 22,2.54$ & 1.22 & $0.90,1.65$ \\
\hline$<1 \mathrm{~h} / \mathrm{d}$ & 1.25 & $0.95,1.63$ & $1.50^{*}$ & $1.08,2.08$ & $2 \cdot 00^{*}$ & $1.42,2.80$ & $1 \cdot 20$ & $0.92,1.56$ \\
\hline $1 \mathrm{~h} / \mathrm{d}$ & $1.64^{*}$ & $1 \cdot 18,2 \cdot 29$ & $1.67^{\star}$ & $1.21,2.29$ & $2 \cdot 69^{\star}$ & $1.93,3.73$ & 0.91 & $0.67,1.23$ \\
\hline $2 \mathrm{~h} / \mathrm{d}$ & $1.96^{*}$ & $1.48,2.59$ & $1.90^{*}$ & $1.45,2.49$ & $3.44^{\star}$ & $2 \cdot 47,4 \cdot 78$ & $1 \cdot 16$ & $0.87,1.53$ \\
\hline $3-4 \mathrm{~h} / \mathrm{d}$ & $2 \cdot 35^{\star}$ & $1 \cdot 72,3.22$ & $2 \cdot 56^{\star}$ & $1.74,3.77$ & $3.42^{*}$ & $2 \cdot 46,4.77$ & 1.09 & $0.82,1.44$ \\
\hline$\geq 5 \mathrm{~h} / \mathrm{d}$ & $2 \cdot 62^{*}$ & $1.90,3.59$ & $3 \cdot 29^{*}$ & $2 \cdot 24,4.83$ & $4.82^{*}$ & $3.13,7.43$ & 1.29 & $0.96,1.72$ \\
\hline$P_{\text {trend }}$ & \multicolumn{2}{|c|}{$<0.01$} & \multicolumn{2}{|c|}{$<0.01$} & \multicolumn{2}{|c|}{$<0.01$} & \multicolumn{2}{|c|}{ NS } \\
\hline
\end{tabular}

SSB, sugar-sweetened beverages.

* Statistically significant at $P<0.05$.

† Model 1: unadjusted.

‡ Model 2: adjusted for age, sex, ethnicity, subjective socio-economic status, parental education level, and tobacco, alcohol and cannabis use. Models for breakfast skipping and consumption of SSB and energy drinks were also adjusted for BMI, whereas models for BMI were also adjusted for breakfast skipping and consumption of SSB and energy drinks.

model 2 indicated that, relative to those who had not used SNS, students who reported using SNS for $<1,2$ and $\geq 5 \mathrm{~h} / \mathrm{d}$ were at 1.67 (95\% CI 1.21, 2.29), 1.90 (95\% CI $1.45,2 \cdot 49)$ and $3.29(95 \%$ CI $2 \cdot 24,4 \cdot 83$ ) times the odds of consuming SSB, respectively, after controlling for covariates and other behaviours. There was no evidence of an association between the use of SNS and excess weight before or after adjustment for age, sex, ethnicity, subjective SES, parental education, alcohol, tobacco and cannabis use, and unhealthy eating behaviour outcomes (breakfast skipping and consumption of SSB and energy drinks).

\section{Discussion}

This study investigated the associations between time spent using SNS and unhealthy eating behaviours (including breakfast skipping, consumption of SSB and energy drinks) and body weight status in a large and diverse sample of Canadian adolescents. Our results did not provide evidence of an association between the use of SNS and excess weight. However, to the best of our knowledge, we are the first to show that the use of SNS is generally associated with increased odds of skipping 
breakfast and consuming SSB and energy drinks in a doseresponse manner before and after adjustment for numerous confounding variables. Our results suggest an opportunity for the use of SNS for public health messages and interventions focusing on healthy eating among adolescents. Indeed, SNS have often been used as a tool for delivering healthcare programmes and services, education, research, intervention and even treatment ${ }^{(21-23,25)}$. Given the popularity of SNS among youth, promoting healthy eating and active living via these web-based platforms may provide potentially potent force to ongoing efforts.

Our results suggest that the amount of time spent on SNS relates to unhealthy eating habits and food choices today's youth are making. These findings corroborate previous research, indicating that sedentary behaviour, particularly screen time, is a predictor of unhealthy eating behaviour ${ }^{(17-19)}$. Research studies have shown that the extent to which sedentary behaviour impacts upon unhealthy dietary patterns may vary by type of activity ${ }^{(34-36)}$ - for example, Borghese et al. ${ }^{(34)}$ provided evidence to suggest that television viewing time is more strongly associated with unhealthy eating choices than total sedentary time. Our results extend these previous findings by suggesting a link between the use of SNS and eating behaviours among youth.

Food advertising plays an important role in food choices and preferences among youth. Social media offers an avenue for food marketers to advertise their products - for example, exposure to food advertisements on television has been shown to increase total food intake by up to $45 \%$ in children ${ }^{(37)}$ and to alter eating choices and behaviours among children ${ }^{(38,39)}$. Research has also shown that children who watch more television are more likely to consume sweets and soft drinks and less likely to consume fruits and vegetables ${ }^{(35,40)}$. With the increasing popularity of SNS, junk food industries have turned to these web-based platforms and target young consumers in their marketing campaign. This would likely add to the public health challenge of improving youth's diets, given the demonstrated innovative strategies and efficiency of television advertisements in impacting children's food choices ${ }^{(41)}$.

Our results indicated an association between the use of SNS and skipping breakfast. Similar to traditional forms of media, such as television and magazines, SNS, particularly Facebook, have been associated with body image concerns among adolescents $^{(42-44)}$ - for example, Tiggemann \& Slater ${ }^{(42,43)}$ indicated that pre-adolescent and adolescent female Facebook users report more appearance concerns and dieting behaviour than non-users and that this link significantly increases with the amount of time spent on this SNS. Appearance comparison has been indicated to be a possible mechanism explaining the association between the use of Facebook and body image concerns $^{(42,43,45)}$. Indeed, Facebook allows users to post photos and provides them with opportunities to compare their appearance with others, thus placing users at a higher risk of body dissatisfaction, which in turn would increase subsequent risk of eating disorders. It is also well known that females are usually more concerned about their body weight than their male counterparts and that they may consider skipping breakfast as a weight-management strategy ${ }^{(46)}$. Another possible explanation of the link between the use of SNS and skipping breakfast is related to the displacement of other activities. It is possible that an increase in the amount of time spent on SNS directly decreases the amount of discretionary time available for eating breakfast. Finally, a shift in circadian rhythmicity (towards a later midpoint of sleep) ${ }^{(47)}$ in adolescence could also explain the link between breakfast skipping and use of SNS. However, participants were not asked about the time of the day they used SNS. Further studies are needed to better understand the association between the use of SNS and breakfast skipping.

Although the present study documented associations between the use of SNS and unhealthy eating behaviours, which are known to have an adverse impact on obesity, our results did not provide evidence of an association between the use of SNS and excess weight before or after adjustment for covariates. This does not support our hypothesis that the use of SNS is associated with excess body weight. Studies using both self-reported and objective weight and height measures have shown that a number of sedentary behaviours are associated with excess weight in children and adolescents ${ }^{(48-51)}$. Although future studies will be needed to better understand and elucidate the conflicting findings on the link between the use of SNS and excess weight, our results suggest that use of SNS may be a type of sedentary behaviour that is not associated with increased body weight among adolescents (possibly up to a certain level). Indeed, the use of SNS is not necessarily reflective of a poor lifestyle in general, as it is possible for youth who use SNS to be physically active as well. Likewise, in their meta-analysis based on fifty-two independent samples, Marshall et $a l^{(52)}$ argued that media-based inactivity may be unfairly implicated in recent epidemiological trends of overweight and obesity among children and adolescents. Regardless, it is important to emphasise that an increase in the amount of time spent on SNS would directly decrease the amount of discretionary time available for physical activity ${ }^{(53)}$.

Despite using a large and diverse sample of Canadian middle school and high school students, our results need to be interpreted in light of the following limitations. First, the sample was restricted to students within the regular and publicly funded school system, and therefore does not represent approximately $8 \%$ of students. In addition, the student non-completion rate due to absenteeism and lack of parental consent may have biased the sample to some degree. Second, causality of the observed associations cannot be determined from cross-sectional data, and future studies using a longitudinal design will be needed to address this issue. Third, the data are based entirely on self-reports and may, thus, be subject to recall bias. Moreover, the use of single questions to measure the outcome variables (i.e. breakfast skipping, consumption of SSB and energy drinks) may raise potential issues related to reliability. More refined and precise measures of unhealthy eating behaviour would be desirable in future studies. Another limitation is related to the possibility of residual confounding by unmeasured variables (e.g. depressive symptoms, body image). Finally, the external generalisability of our findings may be limited to the sample studied.

\section{Conclusions}

To the best of our knowledge, the present study is the first to provide evidence that the use of SNS is associated with greater 
odds of unhealthy eating behaviours among adolescents. Reducing youth's screen-related sedentary time and heightening our efforts with messages on healthy food choices are important public health targets to achieve. Given the popularity of SNS, future studies are needed to better understand the impact of social networks on eating behaviours and risk of excess body weight.

\section{Acknowledgements}

The Ontario Student Drug Use and Health Survey, a Centre for Addiction and Mental Health initiative, was funded in part through ongoing support from the Ontario Ministry of Health and Long-Term Care, as well as targeted funding from several provincial agencies.

The authors' contributions are as follows: H. S.-K. conceived the study, performed the statistical analyses and drafted the manuscript; J.-P. C. contributed to the conception of the study and provided critical reviews of the manuscript; H. A. H. is a co-investigator of the survey on which the analyses are based, contributed to the interpretation of results and provided critical reviews of the manuscript. All the authors read and approved the final version of the manuscript.

None of the authors has any conflicts of interest to declare.

\section{References}

1. Springer AE, Selwyn BJ \& Kelder SH (2006) A descriptive study of youth risk behavior in urban and rural secondary school students in El Salvador. BMC Int Health Hum Rights 6, 3 .

2. Rampersaud GC, Pereira MA, Girard BL, et al. (2005) Breakfast habits, nutritional status, body weight, and academic performance in children and adolescents. I Am Diet Assoc 105, 743-760; quiz 61-62.

3. Szajewska H \& Ruszczynski M (2010) Systematic review demonstrating that breakfast consumption influences body weight outcomes in children and adolescents in Europe. Crit Rev Food Sci Nutr 50, 113-119.

4. Ebbeling CB, Feldman HA, Chomitz VR, et al. (2012) A randomized trial of sugar-sweetened beverages and adolescent body weight. $N$ Engl J Med 367, 1407-1416.

5. Ludwig DS, Peterson KE \& Gortmaker SL (2001) Relation between consumption of sugar-sweetened drinks and childhood obesity: a prospective, observational analysis. Lancet 357, 505-508.

6. de Ruyter JC, Olthof MR, Seidell JC, et al. (2012) A trial of sugar-free or sugar-sweetened beverages and body weight in children. N Engl J Med 367, 1397-1406.

7. Currie C, Zanotti C, Morgan A, et al. (editors) (2012) Social Determinants of Health and Well-Being Among Young People. Health Behaviour in School-aged Children (HBSC) Study: International Report from the 2009/2010 Survey. Copenhagen: WHO Regional Office for Europe.

8. Cali AM \& Caprio S (2008) Obesity in children and adolescents. J Clin Endocrinol Metab 93, S31-S36.

9. Reilly JJ (2006) Obesity in childhood and adolescence: evidence based clinical and public health perspectives. Postgrad Med J 82, 429-437.
10. Thivel D \& Chaput JP (2013) Food consumption in children and youth: effect of sedentary activities. Rev Epidemiol Sante Publique 61, 399-405.

11. Chaput JP, Klingenberg L, Astrup A, et al. (2011) Modern sedentary activities promote overconsumption of food in our current obesogenic environment. Obes Rev 12, e12-e20.

12. Temple JL, Giacomelli AM, Kent KM, et al. (2007) Television watching increases motivated responding for food and energy intake in children. Am J Clin Nutr 85, 355-361.

13. Malik VS, Schulze MB \& Hu FB (2006) Intake of sugarsweetened beverages and weight gain: a systematic review. Am J Clin Nutr 84, 274-288.

14. Timlin MT, Pereira MA, Story M, et al. (2008) Breakfast eating and weight change in a 5-year prospective analysis of adolescents: Project EAT (Eating Among Teens). Pediatrics 121, e638-e645.

15. de Castro JM (2007) The time of day and the proportions of macronutrients eaten are related to total daily food intake. $\mathrm{BrJ}$ Nutr 98, 1077-1083.

16. Speiser PW, Rudolf MC, Anhalt H, et al. (2005) Childhood obesity. J Clin Endocrinol Metab 90, 1871-1887.

17. Pearson N \& Biddle SJ (2011) Sedentary behavior and dietary intake in children, adolescents, and adults. A systematic review. Am J Prev Med 41, 178-188.

18. Kremers SP, van der Horst K \& Brug J (2007) Adolescent screen-viewing behaviour is associated with consumption of sugar-sweetened beverages: the role of habit strength and perceived parental norms. Appetite 48, 345-350.

19. Rehm CD, Matte TD, Van Wye G, et al. (2008) Demographic and behavioral factors associated with daily sugar-sweetened soda consumption in New York City adults. $J$ Urban Health 85, 375-385.

20. Boyd D \& Ellison NB (2007) Social network sites: definition, history, and scholarship. J Comput Mediat Commun 13, 20.

21. Laranjo L, Arguel A, Neves AL, et al. (2015) The influence of social networking sites on health behavior change: a systematic review and meta-analysis. J Am Med Inform Assoc 22, 243-256.

22. Menon IS, Sharma MK, Chandra PS, et al. (2014) Social networking sites: an adjunctive treatment modality for psychological problems. Indian J Psychol Med 36, 260-263.

23. Moreno MA (2013) JAMA pediatrics patient page. Transition of care from pediatric to adult clinics. JAMA Pediatr 167, 684.

24. Rice SM, Goodall J, Hetrick SE, et al. (2014) Online and social networking interventions for the treatment of depression in young people: a systematic review. J Med Internet Res 16, e206.

25. Valle CG, Tate DF, Mayer DK, et al. (2013) A randomized trial of a Facebook-based physical activity intervention for young adult cancer survivors. I Cancer Surviv $\mathbf{7}$, 355-368.

26. Boak A, Hamilton HA, Adlaf EM, et al. (2013) Drug Use Among Ontario Students: 1977-2013: Detailed OSDUHS Findings. CAMH Research Document Series, no. 36. Toronto, ON: Centre for Addiction and Mental Health.

27. Sampasa-Kanyinga H \& Willmore J (2015) Relationships between bullying victimization psychological distress and breakfast skipping among boys and girls. Appetite 89, 41-46.

28. Hamilton HA, Boak A, Ilie G, et al. (2013) Energy drink consumption and associations with demographic characteristics, drug use and injury among adolescents. Can J Public Health 104, e496-e501.

29. World Health Organization (2007) Growth reference data for 5-19 years. http://wwwwhoint/growthref/en/ (accessed May 2014). 
30. Statistics Canada (2006) Census 2006 - 2B (Long Form). Ottawa: Statistics Canada

31. Goodman E, Adler NE, Kawachi I, et al. (2001) Adolescents' perceptions of social status: development and evaluation of a new indicator. Pediatrics 108, E31.

32. Arbour-Nicitopoulos KP, Faulkner GE \& Irving HM (2012) Multiple health-risk behaviour and psychological distress in adolescence. J Can Acad Child Adolesc Psychiatry 21, 171-178.

33. Miller KE, Barnes GM, Melnick MJ, et al. (2002) Gender and $\mathrm{racial} /$ ethnic differences in predicting adolescent sexual risk: athletic participation versus exercise. $J$ Health Soc Behav $\mathbf{4 3}$ 436-450.

34. Borghese MM, Tremblay MS, Leduc G, et al. (2014) Independent and combined associations of total sedentary time and television viewing time with food intake patterns of 9- to 11-year-old Canadian children. Appl Physiol Nutr Metab 39, 937-943.

35. Santaliestra-Pasias AM, Mouratidou T, Verbestel V, et al. (2012) Food consumption and screen-based sedentary behaviors in European adolescents: the HELENA study. Arch Pediatr Adolesc Med 166, 1010-1020.

36. Lissner L, Lanfer A, Gwozdz W, et al. (2012) Television habits in relation to overweight, diet and taste preferences in European children: the IDEFICS study. Eur J Epidemiol 27, 705-715.

37. Harris JL, Bargh JA \& Brownell KD (2009) Priming effects of television food advertising on eating behavior. Health Psychol 28, 404-413.

38. Boyland EJ, Harrold JA, Kirkham TC, et al. (2011) Food commercials increase preference for energy-dense foods, particularly in children who watch more television. Pediatrics 128, e93-e100.

39. Andreyeva T, Kelly IR \& Harris JL. (2011) Exposure to food advertising on television: associations with children's fast food and soft drink consumption and obesity. Econ Hum Biol 9 , 221-233.

40. Vereecken CA, Todd J, Roberts C, et al. (2006) Television viewing behaviour and associations with food habits in different countries. Public Health Nutr 9, 244-250.
41. Bernhardt AM, Wilking C, Adachi-Mejia AM, et al. (2013) How television fast food marketing aimed at children compares with adult advertisements. PLOS ONE 8, e72479.

42. Tiggemann $M \&$ Slater A (2013) NetGirls: the internet, Facebook, and body image concern in adolescent girls. Int J Eat Disord 46, 630-633.

43. Tiggemann M \& Slater A (2014) NetTweens: the internet and body image concerns in preteenage girls. J Early Adolesc 34, 606-620.

44. Meier EP \& Gray J (2014) Facebook photo activity associated with body image disturbance in adolescent girls. Cyberpsychol Behav Soc Netw 17, 199-206.

45. Fardouly J \& Vartanian LR (2015) Negative comparisons about one's appearance mediate the relationship between Facebook usage and body image concerns. Body Image 12, 82-88.

46. Shaw ME (1998) Adolescent breakfast skipping: an Australian study. Adolescence 33, 851-861.

47. Arble DM, Ramsey KM, Bass J, et al. (2010) Circadian disruption and metabolic disease: findings from animal models. Best Pract Res Clin Endocrinol Metab 24, 785-800.

48. Tremblay MS \& Willms JD (2003) Is the Canadian childhood obesity epidemic related to physical inactivity? Int J Obes Relat Metab Disord 27, 1100-1105.

49. Kautiainen S, Koivusilta L, Lintonen T, et al. (2005) Use of information and communication technology and prevalence of overweight and obesity among adolescents. Int $J$ Obes (Lond) 29, 925-933.

50. Ray M \& Jat KR (2010) Effect of electronic media on children. Indian Pediatr $\mathbf{4 7}, 561-568$.

51. Schneider M, Dunton GF \& Cooper DM (2007) Media use and obesity in adolescent females. Obesity (Silver Spring) 15 , 2328-2335.

52. Marshall SJ, Biddle SJ, Gorely T, et al. (2004) Relationships between media use, body fatness and physical activity in children and youth: a meta-analysis. Int J Obes Relat Metab Disord 28, 1238-1246.

53. Mutz DC, Roberts DF \& Van Vuuren D (1993) Reconsidering the displacement hypothesis: television's influence on children's time use. Commun Res 20, 51-75. 